\title{
Determination of the Bromine, Manganese and Antimony in Nicotiana tabacum Solanaceae by Using the Neutron Activation Analysis Technique
}

\author{
Tufic Madi Filho1,2, Elson Barros Ferreira3 ${ }^{3}$ José Roberto Berretta1, \\ Maria da Conceição Costa Pereira1 \\ ${ }^{1}$ Instituto de Pesquisas Energéticas e Nucleares, São Paulo, Brazil \\ ${ }^{2}$ Universidade Paulista-UNIP-SP, Software Engineering Research Group, Paulista University, UNIP, Campus Tatuapé, São \\ Paulo, Brazil \\ ${ }^{3}$ Secretaria da Educação do Estado de São Paulo, São Paulo, Brazil \\ Email: tmfilho@usp.br, macoper@ipen.br
}

How to cite this paper: Filho, T.M., Ferreira, E.B., Berretta, J.R. and Pereira, M. da C.C. (2022) Determination of the Bromine, Manganese and Antimony in Nicotiana tabacum Solanaceae by Using the Neutron Activation Analysis Technique. Materials Sciences and Applications, 13, 91-106. https://doi.org/10.4236/msa.2022.132007

Received: October 7, 2021

Accepted: February 25, 2022

Published: February 28, 2022

Copyright $\odot 2022$ by author(s) and Scientific Research Publishing Inc. This work is licensed under the Creative Commons Attribution International License (CC BY 4.0).

http://creativecommons.org/licenses/by/4.0/

(c) (i) Open Access

\begin{abstract}
Tobacco addiction has been mentioned as a leading cause of preventable illnesses and premature disability. Smoking is the main cause of lung cancer and one of the factors that most contribute to the occurrence of heart diseases, among others. The herbaceous species Nicotiana tabacum is a plant of the solanaceae family used for tobacco production. Some authors have conducted research about heavy metals and the toxicity of tobacco. It is, frequently, found in low concentrations in the ground, and superficial and underground waters, even though they do not have environmental anthropogenic contributions. However, with the increase of industrial activities and mining together with the agrochemical use of contaminated organic and inorganic fertilizers, an alteration of the geochemical cycle occurs. As a consequence, the natural flow of these materials increases and is released into the biosphere, where they are often accumulated in the superior layer of the ground, accessible to the roots of the plants. During planting and plant development, fertilizers and insecticides, including organochlorines and organophosphates, are used; consequently, the smoke from cigarette smoking presents various toxic substances, such as bromine $(\mathrm{Br})$, manganese $(\mathrm{Mn})$ and antimony $(\mathrm{Sb})$, elements studied in this work. The procedures for the preparation of the samples were carried out in our laboratories and submitted to irradiation with thermal neutrons at Nuclear and Energy Research Institute (IPEN/CNEN-SP), in the Atomic Energy Institute IEA-R1 research reactor. The irradiated material
\end{abstract}


was, then, analyzed by gamma spectrometry, using a high purity germanium detector (HPGe).

\section{Keywords}

Nicotiana tabacum, Bromine, Manganese, Antimony, Neutron Activation Analysis

\section{Introduction}

The habit of smoking is very old in human civilization. Historical records related to tobacco culture date back to approximately four thousand years ago, the period in which tobacco began to be cultivated and used. However, tobacco was already cultivated by the Mayans in the North and Central American region. In America, some indigenous peoples already used tobacco in religious ceremonies, believing that inhaling the smoke produced by it brought them closer to the gods [1].

Between 1650 and 1750, with the great expansion of the overseas trade, tobacco was distributed all over the world. In North American lands, more precisely the English colony of Virginia, which had perfect soil and climates, the cultivation of tobacco on a commercial scale began.

One of the factors that most influenced tobacco consumption at the beginning of the 19th century was the wars in Europe, where the commercialization of new types of cigarettes and derivatives from different parts of the world began. Another important fact was the beginning of the consumption of cigars in Europe, through French and English soldiers, during the period of the Peninsular War (1808-18013), which spread throughout the continent, but over time the cigarette surpassed it [2].

In the machine era, cigarettes became more accessible due to their easy and quick manufacture, thus lowering their price compared to other tobacco-derived products. With that, the acquisition for the low-income class became easier, but the factor that was decisive in the popularization of cigarettes around the world was the two great wars [3].

Over the years, in the 1960s, movies and advertisements transformed the habit of smoking into a fashion phenomenon that was perpetuated until the 1990s, a period that marked the beginning of tobacco control actions, thus reducing consumption of cigarettes [4]. But policies to encourage the free production and sale of tobacco, especially in China and Eastern Europe, have kept the tobacco market in the world constant.

Problems related to the exposure and use of tobacco and its derivatives continue to occur and, since it is a public health issue, smoking and its risks continue to merit the attention of science [5] [6]. Currently, several countries question smoking, such as Ireland, England, Japan and Israel. 
In Brazil, the anti-smoking law started being implemented in states, as in the state of São Paulo with law number 13.541, dated May 7, 2009. In 2014, the Federal Law 12,546 came into force, prohibiting smoking of cigarillos, cigars, pipes, hookahs and other products in places of collective use, public or private, such as halls and corridors of condominiums, restaurants and clubs. This situation stimulated the development of this work.

Smoking has been ranked as one of the leading causes of preventable illnesses and premature disabilities. It is known that smoking is the main cause of lung cancer and one of the factors that most contribute to the onset of heart diseases, among others [6]. Passive smoking is already considered the third leading cause of inevitable death in the world, behind active smoking and excessive consumption of in situ alcoholic beverages [7], involving both inhalation of primary and secondary stream smoke and exhaled smoke [8].

The chemical constitution of the smoke produced in the combustion process is complex, containing several types of components, several dozens of them being carcinogenic.

Tobacco (Nicotiana tabacum L.) destined to Brazilian industries is cultivated mainly in southern Brazil, comprising two states, Rio Grande do Sul, Santa Catarina [9] [10]. The cultivation of tobacco is one of the main agricultural activities in Rio Grande do Sul, the state with the largest planted area (180,000 ha), where Virginia and Burley types are grown, accounting for $82.7 \%$ and $16.4 \%$ of the area, respectively, with the remainder being common tobacco [11] [12]. The main types or qualities of tobacco planted in Brazil have different maturation periods. The Virginia species has its peculiarities, as it has a longer cycle. The feet are not cut, however its leaves are removed, respecting the ripeness. The Burley species, which has a shorter cycle, is harvested only once, is cut very close to the ground, has a firm and reasonably hard stem. After cutting it is put to dry upside down in sheds, covered and without walls to facilitate the drying.

The culture provides work to large and small farmers, with an important socio-economic role, besides constituting raw material for an important industrial complex located in the region. The tobacco industry generates more than US \$ 5 billion a year in Brazil alone, creating more than 2 million jobs, with around 700 thousand direct jobs in the countryside and in industry [11] [12].

\subsection{Chemical Composition of Tobacco}

The tobacco leaf may contain more than 2000 different constituents, depending on the growing region, soil, drying and storage [13]. The leaf combustion in the form of smoke has a complex chemical constitution, presenting various types of components: gases such as carbon monoxide, nitrogen dioxide, formaldehyde, polycyclic aromatic hydrocarbons, as well as metallic and radioactive elements [6] [8] [14]. The particulate fraction of the tobacco contains nicotine, hydrocarbons and trace elements of less volatile metals that are, also, found in the gas phase, making an important source of air pollution, including indoor air pollu- 
tion [8] [14] [15] [16]. These constituents have some influence on the human behavior and on health. The substances analyzed in this paper are described below:

\subsection{Bromine (Br)}

Bromine belongs to the group of nonmetals (halogens) and it is the only liquid element among them; it is very volatile at room temperature. It has, among its main physical and chemical properties, the atomic weight of 79.90, the melting point of $\left(-7.2^{\circ} \mathrm{C}\right)$, and the boiling point of $58.8^{\circ} \mathrm{C}$. It may present different oxidation states, the most common are: $1^{-}, 1^{+}, 3^{+}$and $5^{+}$[17]. Bromine occurs in the form of salts diffused in some rocks and saline waters from natural sources and it is part of the seawater, which contains about $85 \mathrm{ppm}$ in the form of bromide $\left(\mathrm{Br}^{-}\right)$[18].

This element has application in the manufacture of sprays, non-flammable agents, products for water purification, colorants, photography (silver bromide, $\mathrm{AgBr}$ ), disinfectants, insecticides and others. Methyl bromide organic compound, $\mathrm{CH}_{3} \mathrm{Br}$, contains $83 \%$ bromine and has application in agriculture as a pesticide and as grain fumigants to control insects, bacteria, and rodents in the stored grain, but, it presents the inconvenient consequence of its effect on the ozone layer [19] [20]. Bromine is found at trace levels in humans, although its functions are not known yet, since one of the essential elements and some of its compounds are used in the treatment of epilepsy and as sedatives [20]. However, bromine is highly toxic and, in small amounts (10 ppm), either inhaled or through the dermis, may cause health problems, leading to death. It is, also, very irritating to the eyes and throat and causes painful inflammations in contact with the skin [20].

\subsection{Manganese (Mn)}

It is an essential chemical element to all life forms, with both structural and enzymatic functions [21] [22] [23]. It presents seven states of oxidation, the main ones are: $\mathrm{Mn}^{2+}, \mathrm{Mn}^{3+}, \mathrm{Mn}^{4+}$ and $\mathrm{Mn}^{7+}$. Elemental manganese has a specific density of 7.21 to $7.4 \mathrm{~g} / \mathrm{cm}^{3}$, depending on the allotropic form, a melting point of $1260^{\circ} \mathrm{C}$, boiling point of $1962^{\circ} \mathrm{C}$. Oxides, carbonates and silicates of manganese are the most abundant compounds in nature and are characterized by being insoluble in water [21].

Among the main industrial applications causing the occurrence of manganese exposure are: the manufacture of safe phosphorus, dry batteries, non-ferrous alloys containing copper and nickel, porcelain enamel, fertilizers, fungicides, animal feeding, welding electrodes, magnets, catalysts, glasses, paint, electrical materials and pharmaceuticals (chlorides, oxides, and manganese sulfates), with the most significant forms of exposure occurring by manganese fumes and dust [21].

According to Etges [24], it is common to find high concentrations of manganese in soils and sediments where the cultivation of the tobacco plant occurs, as 
the content of this element is very high in the basaltic rocks that gave origin to the soils of the cultivation regions. There is, also, the possibility of residues coming from insecticides, fungicides, pesticides, fumigant and fertilizers applied in crop property.

\subsection{Antimony (Sb)}

Antimony (Sb) (atomic number 51; atomic mass $121.75 \mathrm{~g} / \mathrm{mol}$; density 6.684 $\mathrm{g} / \mathrm{cm}^{3}$; melting point $\left.631^{\circ} \mathrm{C}\right)$ occurs naturally as a sulfide ore, stibnite $\left(\mathrm{Sb}_{2} \mathrm{~S}_{3}\right)$ and valentinite $\left(\mathrm{Sb}_{2} \mathrm{O}_{3}\right)$. Antimony in its trivalent state ( $\mathrm{Sb}$ III) is considered a clastogenic agent, but not mutagenic, and this species is responsible for the toxic effects. Studies on antimony have not shown the carcinogenicity of this metal in humans, although antimony trioxide $\left(\mathrm{Sb}_{2} \mathrm{O}_{3}\right)$ is suspected to be a possible carcinogen. The available information on the toxicological aspects of antimony comes from studies of pharmacological antimony-based organic compounds [25].

\section{Objective}

The objective of this work was to perform a comparative analysis of bromine, manganese and antimony contents in natural leaves and in the industrially processed tobacco in order to verify whether there is transference of the elements between the natural leaves and those which are industrially processed, with either a decrease or an increase in the process of industrialization, due to the industrial processing chemistry. For this experiment, tobacco and totally industrialized materials obtained in Rio Grande do Sul were used. For the analysis of the elements, the neutron activation analysis technique was used since it allows a multi element analysis.

\section{Materials and Methods}

In the development of this work, the following items were used: Gamma Spectrometry System composed by an HPGe of $30 \%$ of relative efficiency for the measurement of the material powders irradiated in the Atomic Energy Institute (IEA-R1) reactor, under a thermal neutron flux [26].

The Nuclear Research Reactor IEA-R1 of the Instituto de Pesquisas Energéticas eNucleares is a swimming pool type reactor, designed by "Babcock \& Wilcox Company," with its first criticality on September 16, 1957.

For the application of Neutron Activation Analysis (NAA), a Pneumatic Transfer System was used to transport and transfer materials to be irradiated for a maximum time of 5 minutes, and an irradiation system element for a long time irradiation. Both systems were used in this work. Below, samples of leaves, stems, roots of Nicotiana Tabacum Solanaceae plant and local soil in the superficial layer 0 - $50 \mathrm{~mm}$ and $150-200 \mathrm{~mm}$ collected in the area of Vale do Rio Pardo, municipal district of Boqueirão do Leão (Rio Grande do Sul) (Figure 1 and Figure 2). 


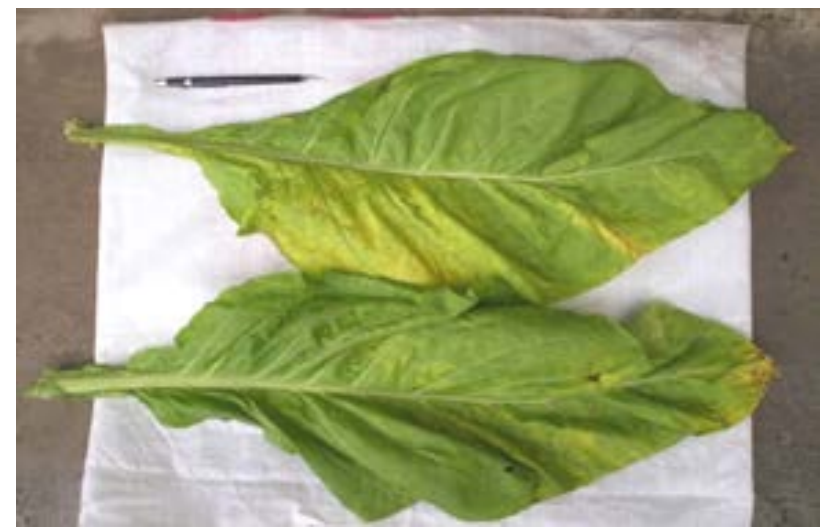

Figure 1. Leaf of Nicotiana tabacum L.

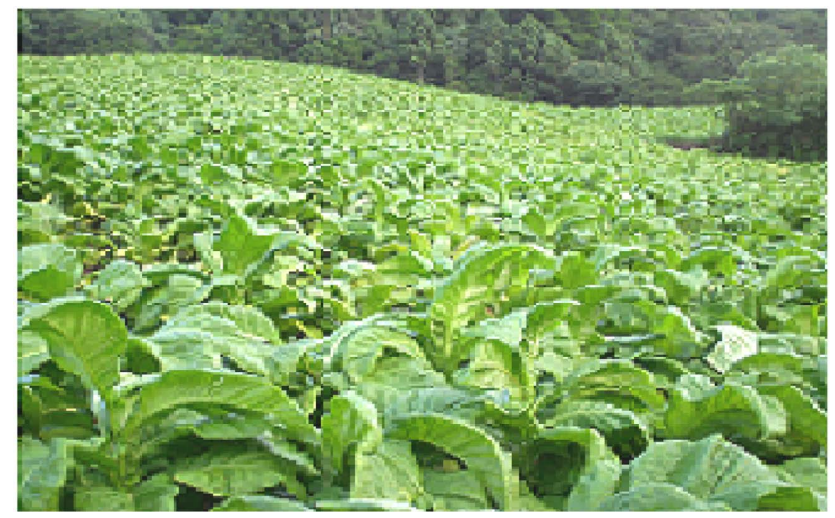

Figure 2. Tobacco plantation.

All the samples were conditioned in non-toxic plastic poly vinyl chloride (PVC) transparent film packages for transportation. The leaves were dried in a greenhouse $\left(50^{\circ} \mathrm{C}-60^{\circ} \mathrm{C}\right)$, the roots and the stems were washed in running water to eliminate soil remains and, later, submitted to evaporation in the greenhouse $\left(50^{\circ} \mathrm{C}\right)$, Figure 3.

The soil samples were air-dried and submitted to particle size separation (ABNT, NBR 7181/2016) [27]. The leaves, roots and stems were milled and transferred to the heater-muffle in porcelain crucibles, with temperature gradient of up to $500^{\circ} \mathrm{C}$. The resulting material was transferred to polyethylene capsules and submitted to irradiation. Table 1 shows the number and respective mass of the samples.

Samples of chopped tobacco contained in cigarettes from brands sold in Brazil were prepared by being randomly removed from cigarette packs that had the paper and filter removed for the use of tobacco only.

Then, the samples were submitted to the muffle furnace (FORNITEC $1200 \mathrm{~T}$ $220 \mathrm{~V}$ ) in porcelain crucibles where they were heated at a temperature of $400^{\circ} \mathrm{C}$ for 50 minutes, until they were transformed into ashes that were weighed in an analytical balance (SARTORIUS. BP 210 S) packed in Eppendorf Tube suitable for irradiation, and their specifications followed the sequence of the natural samples according to Table 2 . 


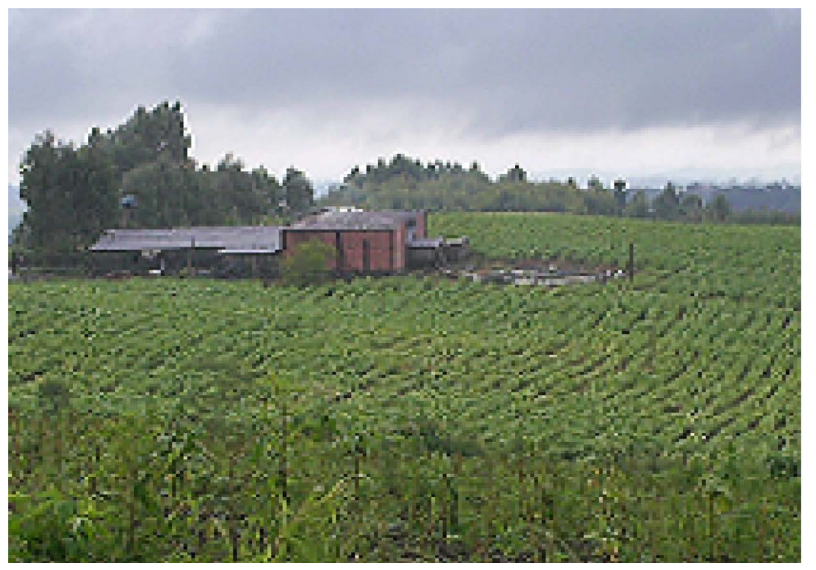

Figure 3. Sheet drying unit. Greenhouse inside the plantation Municipality of Boqueirão do Leão-Rio Grande do Sul.

Table 1. Natural leaves samples and respective mass.

\begin{tabular}{cc}
\hline Natural Leaves & Mass $(\mathrm{g})$ \\
\hline 1A & 0.3064 \\
2B & 0.3053 \\
3C & 0.3013 \\
4D & 0.3027 \\
5E & 0.3055 \\
\hline
\end{tabular}

Table 2. Industrialized samples and their masses.

\begin{tabular}{cc}
\hline Samples/ash & Mass $(\mathrm{g})$ \\
\hline $6 \mathrm{~F}$ & 0.2524 \\
$7 \mathrm{G}$ & 0.2584 \\
$8 \mathrm{H}$ & 0.253 \\
$9 \mathrm{I}$ & 0.2512 \\
$10 \mathrm{~J}$ & 0.2538 \\
\hline
\end{tabular}

\section{Preparation of Synthetic Standards}

For the qualitative and quantitative comparison of the chemical elements to be determined in natural samples and in the ashes, synthetic standards were prepared from the dry weighing stage, in analytical scales (Sartorius, BP 210S), with masses of the respective analytical compounds. Primary standard antimony trioxide $\left(\mathrm{Sb}_{2} \mathrm{O}_{3}\right)$ 99.999\% (Sigma-Aldrich), primary standard sulphate of copper $\left(\mathrm{CuSO}_{4} \cdot 5 \mathrm{H}_{2} \mathrm{O}\right)$ 99.999\% (Sigma-Aldrich), powdered metal zinc $99.995 \%$ (Sigma-Aldrich) and GYP-D standard, packed in Eppendorf tube, composition of the standards characterized according to Table 3.

\subsection{Activation Analysis with Neutrons (AAN)}

AAN is a nondestructive method of analysis that allows, in many cases, to determine the concentrations of 20 to 40 elements in a single sample. It consists of 
Table 3. Composition of synthetic standards.

\begin{tabular}{cccc}
\hline \multicolumn{3}{c}{ MIX Standards } \\
\hline Standard & scopper $(\mathrm{g})$ & zinc $(\mathrm{g})$ & antimony $(\mathrm{g})$ \\
MIX-52210 & 0.1081 & 0.1129 & 0.1022 \\
MIX-52310 & 0.1089 & 0.1195 & 0.1060 \\
\hline & & GYP-D Standard & \\
\hline Standard & barium $(\mu \mathrm{g} / \mathrm{g})$ & manganese $(\mu \mathrm{g} / \mathrm{g})$ & bromine $(\mu \mathrm{g} / \mathrm{g})$ \\
GYPD-1 & 53.7 & 100.4 & 0.65 \\
\hline
\end{tabular}

a neutron bombardment in a given material, followed by the measurement of the induced radioactivity. In general, irradiation is performed with thermal or epithermal neutrons and the resulting radioactivity is measured using gamma ray spectrometry emitted by each radioisotope.

The isotopes produced in the activation process have their own emission characteristics (half-life and particle energy or gamma radiation emitted) and it is possible to make quantitative determinations of the concentration by comparison with standards or by the direct method. The elements are identified as a function of the emitted gamma energy and their quantity is determined by the areas of energy peaks related to activated patterns, together with the samples [28] [29].

For the AAN, a neutron source, usually a research reactor, an ultra-pure Ge type high energy (HPGe) detector and a Multichannel Analyzer (MCA), which provides the energy spectrum of the gamma rays emitted by the irradiated material, are required [28].

\subsection{Relative or Comparative Instrumental Method}

It is the most used method for the quantification of radionuclides. The samples and patterns of the element to be analyzed are irradiated simultaneously under the same neutron flux. Then, they are measured under the same counting conditions. The concentration of the element of interest is calculated by comparing the activity measured between the sample and the standard. It is important that both may have well-defined compositions; the standard needs to be made from the same sample material, irradiated and analyzed under the same conditions. The isotopic mass is determined from the ratio of the sample and standard activities. The relative analysis is not very satisfactory for "multi-element" samples since it is practically impossible to produce a "multi-element" pattern with all detectable elements having the precision, volume, size and shape equal to those of the sample. Reference materials that are certified as standards may be used. Although it is a simple method, it is destructive and requires the preparation of a standard sample set so that each element may be determined [30].

\subsection{Absolute or Parametric Method}

Detectors are used to measure the flux of neutrons. The type of detector depends 
on the magnitude of the shock section, the neutron beam, the irradiation time and the manufacturing properties of the activation detector [31].

Homemade software (Figure 4) was developed to calculate the neutron thermal flux and the isotopic fraction in the sample in order to use the NAA absolute method.

\subsection{Non-Relative Method $\left(\mathrm{K}_{0}\right)$}

Also known as the $\mathrm{K}_{0}$ or semi-parametric method. In multi-element AAN, standards are co-irradiated to all elements in relation to each element of the chosen comparator. Once a factor has been calibrated (experimentally determined) for each of the elements-the $\mathrm{k}$ factor, only one comparator element has to be used in routine measurements, instead of individual standards for each element. Currently there are $k_{0}$ values for 140 reactions $(n, \gamma)$. The advantage of the method is the elimination of uncertainties arising from the use of a standard and the use of nuclear parameters extracted from the literature, but it includes the uncertainties of $\mathrm{k}_{0}$, which do not exceed $3.5 \%$. $\mathrm{K}_{0}$ is a ratio between the irradiating equipment and the detection system already characterized. The $\mathrm{k}$ factors are only valid for a specific detector and sample shape, count geometry and very specific irradiation procedure as well [32].

\section{Results}

Figure 5 shows the gamma spectra resulting from the comparison between the three natural leaf samples (1A, $2 \mathrm{~B}$ and $3 \mathrm{C}$ ).

The comparison between 03 natural leaf samples (1A, 2B, 3C) demonstrate that the sample had coincident energies and allowed to evidence the presence of

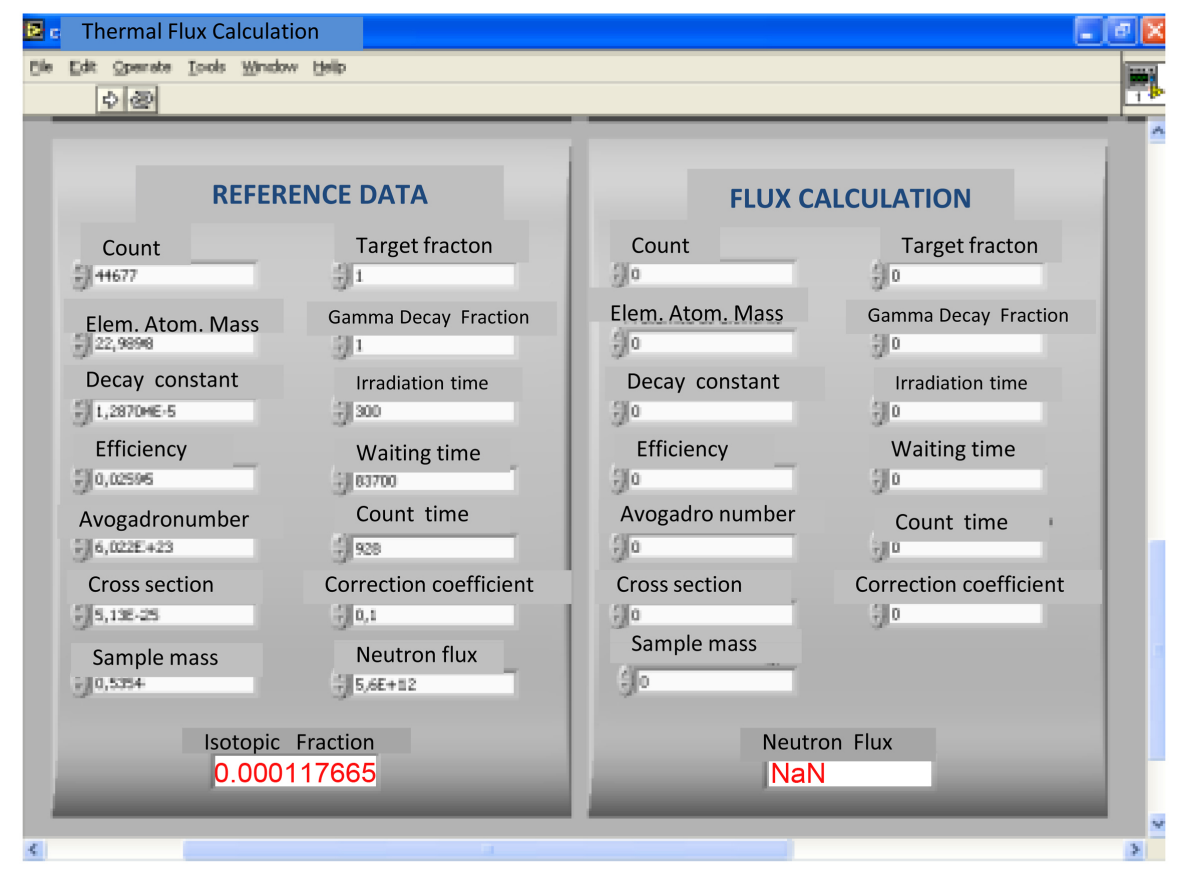

Figure 4. Screen of Homemade software. 
the chemical elements potassium $(\mathrm{K})$, sodium $(\mathrm{Na})$ and bromine $(\mathrm{Br})$.

Figure 6 shows the gamma spectra resulting from the comparison among the GYPD-1 synthetic pattern, the $4 \mathrm{D}$ sample and $8 \mathrm{H}$ ash.

Although the GYPD-1 standard consists of barium, bromine and manganese, it was only possible to show the energies of the manganese element, as shown in Figure 6, demonstrating that the elements barium and bromine were not activated in the standard.

Figure 6 shows coincident energies of the manganese element in the ash sample $(8 \mathrm{H})$ and in the natural leaf sample $(4 \mathrm{D})$, indicating that the chemical element manganese is present in the tobacco leaves before the industrialization

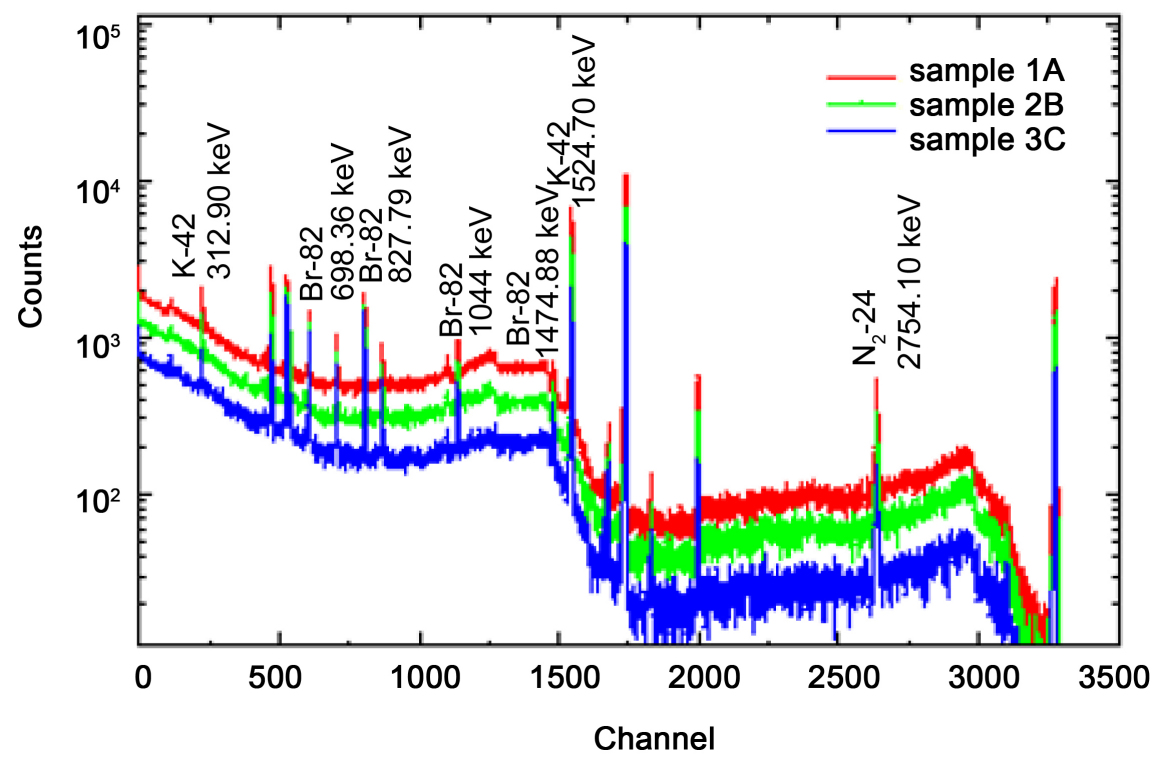

Figure 5. Comparison between natural leaf samples.

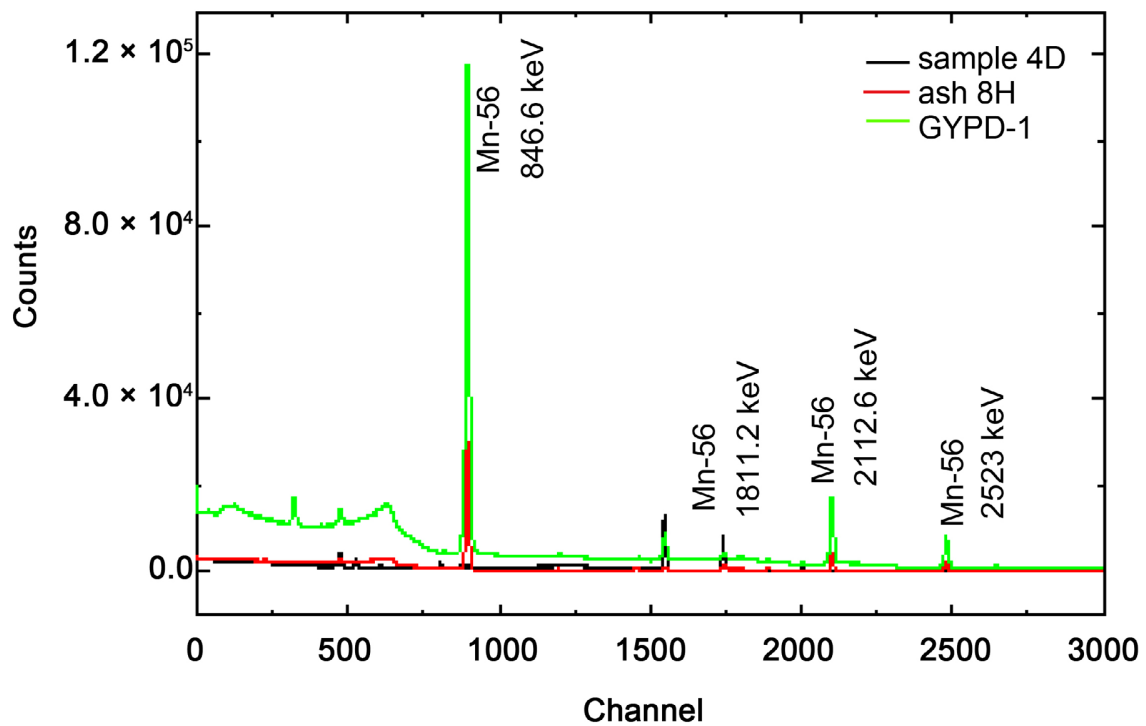

Figure 6. Matching gamma energies in the comparison between the GYPD-1 synthetic Patterns, the $4 \mathrm{D}$ sample and $8 \mathrm{H}$ ash. 
process.

Figure 7 shows the gamma spectra resulting from the comparison between the MIX 52310 synthetic pattern, natural leaves 3C and 6F.

Comparing the MIX 52310 standard with the $3 \mathrm{C}$ natural leaf sample and $6 \mathrm{~F}$ ash, it is possible to observe that the antimony element is present in the $6 \mathrm{~F}$ ash sample.

This element was also determined in the work of Munita [33], where it is possible to observe the concentration of antimony in the samples of three different brands of Brazilian cigarettes analyzed by AAN, ranging from $0.084 \mathrm{ppm}$ to $0.45 \mathrm{ppm}$.

Table 4 presents some information used in the isotope analyses detected in the irradiated samples.

Table 5 presents the fraction of isotopes found in the samples of ashes (industrialized) and in the natural leaves, under conditions of irradiation in the reactor and in the pneumatic system, from the absolute and comparative methods.

Table 5 shows the values of the elements quantified by the absolute and comparative methods. Only manganese was quantified using comparative method. It may be noted that there is little variation between the values detected by the two methods. By the absolute method, manganese was quantified only in $8 \mathrm{H}$ and $4 \mathrm{D}$ samples because, to analyze $6 \mathrm{~F}$ and $3 \mathrm{C}$ samples, a waiting time of $48 \mathrm{~h}$ was required. Mn-56 half-life $\left(\mathrm{t}_{1 / 2}\right)$ is 2.58 hours, and, then, the activated manganese had already decreased when measurements were initiated.

Table 5 and Figure 8 show the fraction of the isotopes detected in the irradiated samples, according to the irradiation system. There are no established values of manganese in $3 \mathrm{C}$ and $6 \mathrm{~F}$ samples because it could not be observed with

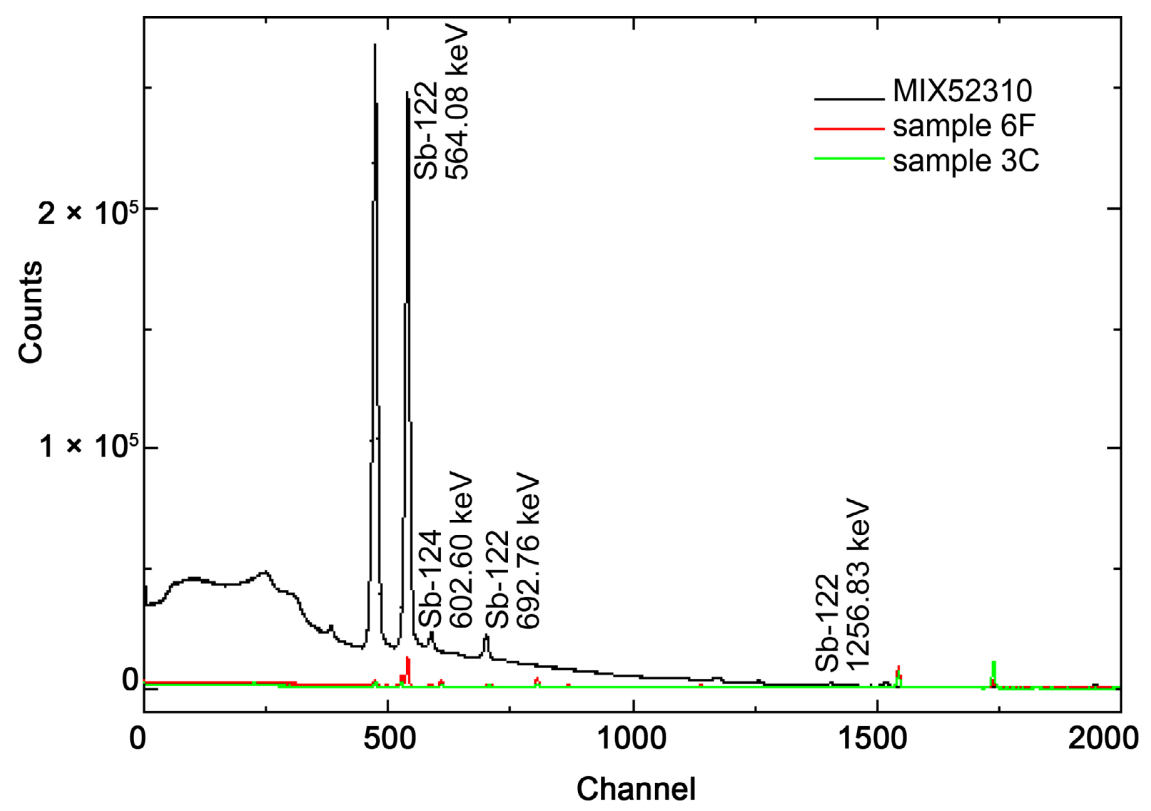

Figure 7. Gamma spectra for comparison between the MIX 52310 pattern, natural leaves $3 \mathrm{C}$ and $6 \mathrm{~F}$ ash. 


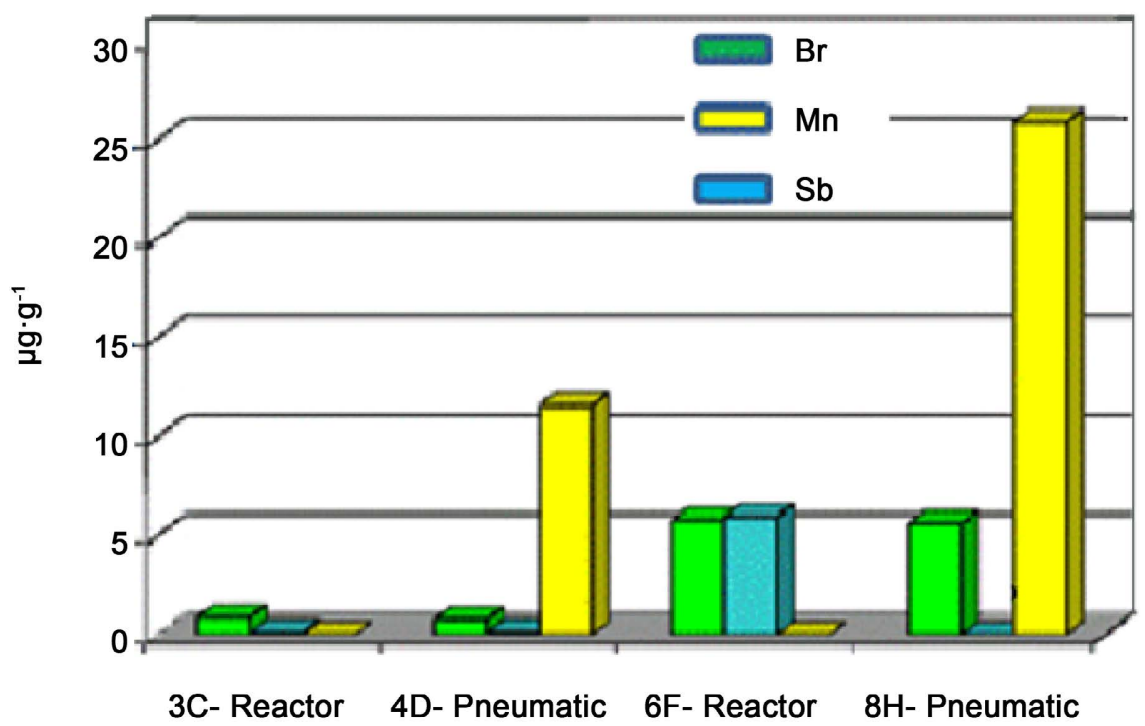

Figure 8. Isotopic fraction of the detected elements.

Table 4. Data of the isotopes in the irradiated samples.

\begin{tabular}{|c|c|c|c|c|c|c|c|}
\hline $\begin{array}{l}\text { Isotope } \\
\text { Target }\end{array}$ & $\begin{array}{l}\text { Isotope } \\
\text { Formed }\end{array}$ & $\begin{array}{c}\text { Isotopic } \\
\text { Abundance } \\
(\%)\end{array}$ & $\begin{array}{c}\sigma \\
\text { (barn) }\end{array}$ & $\begin{array}{l}\text { Nuclear } \\
\text { Reaction }\end{array}$ & $\begin{array}{c}\text { Half } \\
\text { Life } \\
\left(\mathrm{t}^{1 / 2}\right) \\
\mathrm{h}\end{array}$ & $\begin{array}{c}\text { Gamma } \\
\text { Energy } \\
(\mathrm{keV})\end{array}$ & $\begin{array}{c}\text { Gamma } \\
\text { Abundance } \\
\quad(\%)\end{array}$ \\
\hline Mn-55 & $\mathrm{Mn}-56$ & 100 & 13.2 & ${ }^{55} \mathrm{Mn}(\mathrm{n}, \mathrm{g}){ }^{56} \mathrm{Mn}$ & 2.58 & $\begin{array}{c}846.76 \\
1810.72 \\
2113.05\end{array}$ & $\begin{array}{c}98.87 \\
27.119 \\
14.34\end{array}$ \\
\hline $\mathrm{Sb}-121$ & Sb-122 & 57.30 & 0.0055 & ${ }^{121} \mathrm{Sb}(\mathrm{n}, \mathrm{g}){ }^{122} \mathrm{Sb}$ & 64.8 & $\begin{array}{l}564.24 \\
692.65\end{array}$ & $\begin{array}{c}69.30 \\
3.78\end{array}$ \\
\hline $\mathrm{K}-41$ & $\mathrm{~K}-42$ & 6.73 & 1.45 & ${ }^{41} \mathrm{~K}(\mathrm{n}, \mathrm{g}){ }^{42} \mathrm{~K}$ & 12.36 & 1524.58 & 18.80 \\
\hline $\mathrm{Na}-23$ & $\mathrm{Na}-24$ & 100 & 0.513 & ${ }^{23} \mathrm{Na}(\mathrm{n}, \mathrm{g})^{24} \mathrm{Na}$ & 14.96 & $\begin{array}{l}1368.60 \\
2754.00\end{array}$ & $\begin{array}{c}100 \\
99.94\end{array}$ \\
\hline Br-81 & Br-82 & 49.31 & 2.58 & ${ }^{81} \mathrm{Br}(\mathrm{n}, \mathrm{g}){ }^{82} \mathrm{Br}$ & 353 & $\begin{array}{c}554.35 \\
619.11 \\
698.37 \\
776.52 \\
827.83 \\
104.08 \\
1317.47 \\
1474.88\end{array}$ & $\begin{array}{l}70.76 \\
43.44 \\
28.49 \\
83.54 \\
24.03 \\
27.23 \\
26.48 \\
16.32\end{array}$ \\
\hline
\end{tabular}

activation by the reactor. The same happens with the antimony in the $8 \mathrm{H}$ sample, activated by the pneumatic system. The bromine element is the only one that appears in all the samples, demonstrating that could be detected both in the natural and in the industrialized leaves.

Figure 8 presents the isotopic fraction detected in the samples irradiated according to the irradiation system. 
Table 5. Isotopic fraction of the detected element.

\begin{tabular}{ccccc}
\hline \multirow{2}{*}{ Sample } & \multicolumn{4}{c}{ Element } \\
\cline { 2 - 5 } & $\begin{array}{c}\text { Absolut } \\
\text { Bromine } \\
\mu \mathrm{g} \cdot \mathrm{g}^{-1}\end{array}$ & $\begin{array}{c}\text { Antimony } \\
\mu \mathrm{g} \cdot \mathrm{g}^{-1}\end{array}$ & $\begin{array}{c}\text { Manganese } \\
\mu \mathrm{g} \cdot \mathrm{g}^{-1}\end{array}$ & $\begin{array}{c}\text { Manganese } \\
\mu \mathrm{g} \cdot \mathrm{g}^{-1}\end{array}$ \\
\hline Manufactured & & & & \\
6F (Reactor) & 5.768 & 5.9529 & 25.2 \\
8H (pneumatic) & 5.6174 & & 25.906 & \\
Natural Leaves & & & & \\
3C (Reactor) & 0.8869 & 0.1081 & 16.2 \\
4D (pneumatic) & 0.7604 & 0.1298 & 1.5956 & \\
\hline
\end{tabular}

The presence of bromine in samples of natural leaves may be related to the continued use of methyl bromide based anti-sprouting, as well as the use of rodenticides that possess this element in their chemical composition. It was, also, possible to identify the presence of bromine in the ash where, not only the transfer among the leaves and the processed tobacco occurred, but, also a considerable increase of this element was verified (Table 5 and Figure 8).

Although manganese is an essential element available in the soil and, therefore, naturally absorbed by the roots of the plants, this element is present in the natural leaves and, in a greater amount, in the ashes, demonstrating not only the transfer but, also, an increase, possibly due to the additives applied in the process of cigarette industrialization (Table 5 and Figure 8. An excess of this element in the body may compromise the Central Nervous System (CNS) and lungs.

The antimony element was not identified in the leaf samples, but, its presence in the ashes demonstrated that this element starts composing the smoke from the process of cigarette industrialization (Table 5 and Figure 8). The antimony element presents, although with less toxicity, effects similar to those of arsenic, being able to produce harmful effects to the respiratory and cardiovascular system.

\section{Conclusions}

In this research it can be noted that the irradiated samples are very active and it is necessary to wait for a cooling time to be able to handle them. It can also be noticed that some elements do not appear in the first measurements but appear after a decay time, other elements decay so that they could not be detected after the cooling time.

The comparative analysis of the samples of Nicotiana tabacum leaves and the ashes of shredded tobacco using AAN allowed identifying the presence of elements associated with the plant's cultivation, but also with the cigarette industrialization process.

Considering the presence of the elements detected in this work and the degree 
of toxicity that each one can present, it is interesting that these elements, too, are controlled by ANVISA (Sanitary Surveillance Agency), which are present in the primary and secondary currents, the total emission of cigarette smoke.

It is important to note that from the combustion of cigarettes, a part of these elements is made available in environments, which can be inhaled by both active and passive smokers.

The Neutron Activation Analysis (NAA) also allowed to observe the occurrence of elements such as potassium and sodium in the leaves and ashes, however, considering future studies with longer irradiation times of the samples, it is possible that other elements not identified in these analyzes may be present.

\section{Conflicts of Interest}

The authors declare no conflicts of interest regarding the publication of this paper.

\section{References}

[1] Mishra, S. and Mishra, M.B. (2013) Tobacco: Its Historical, Cultural, Oral and Periodontal Health Association. Journal of International Society of Preventive \& Community Dentistry, 3, 12-18. https://doi.org/10.4103/2231-0762.115708

[2] Daniels, H. (2015) When the Smoke Cleared: Tobacco Supply and Consumption by the British Expeditionary Force, 1914-1918. French Journal of British Studies, 20, 1-24. https://doi.org/10.4000/rfcb.218

[3] Bonnie, R.J., Stratton, K. and Wallace, R.B. (2007) Epidemiology of Tobacco Use: History and Current Trends. The National Academy of Sciences Engineering Medicine Press, Washington DC, 41-75. https://www.nap.edu

[4] Cummings, K.M. (2002) Programs and Policies to Discourage the Use of Tobacco Products. Oncogene, 21, 7349-7364. https://doi.org/10.1038/sj.onc.1205810

[5] Jha, P. (2020) The Hazards of Smoking and the Benefits of Cessation: A Critical Summation of the Epidemiological Evidence in High-Income Countries. eLife, 9, e49979. https://doi.org/10.7554/eLife.49979

[6] Marques, A.C.P.R., Campana, A., Gigliotti, A.P., Lourenço, M.T.C., Ferreira, M.P. and Laranjeira, R. (2001) Consensus on the Treatment of Nicotine Dependence. Brazilian Journal of Psychiatry, 23, 200-214. https://doi.org/10.1590/S1516-44462001000400007

[7] Barta, J.A., Powell, C.A. and Wisnivesky, J.P. (2019) Global Epidemiology of Lung Cancer. Annals of Global Health, 85, 8. https://doi.org/10.5334/aogh.2419

[8] Naeem, Z. (2015) Second-Hand Smoke-Ignored Implications. International Journal of Health Sciences, 9, 5-6. https://doi.org/10.12816/0024103

[9] Kist, B.B., et al. (2019) Anuáriobrasileiro do Tabaco. Brazilian Tobacco Yearbook. Santa Cruz do Sul, EditoraGazeta, 132 p.

[10] Boettcher, R., Zappe, A.L., Oliveira, P.F., Machado, E.L., Rodriguez, A.A.L. and Lopez, D.A.R. (2020) Carbon Footprint of Agricultural Production and Processing of Tobacco (Nicotiana tabacum) in Southern Brazil. Environmental Technology \& Innovation, 18, Article ID: 100625. https://doi.org/10.1016/j.eti.2020.100625

[11] Riquinho, D.L. and Hennington, E.A. (2012) Health, Environment and Working Conditions in Tobacco Cultivation: An Review of the Literature. Ciência \& Saúde 
Coletiva, 17, 1587-1600. https://doi.org/10.1590/S1413-81232012000600022

[12] Campos, E., Brasil, V.I., Alves, S.R., Rosa, A.C.S., Geraldino, B., Meira, B.C., Cunha, V., Cavalcante, T.M., Turci, S., Mello, M.S.C. and Otero, U. (2020) Occurrence of Green Tobacco Sickness and Associated Factors in Farmers Residing in Dom Feliciano Municipality, Rio Grande do Sul State, Southern Region of Brazil. Cadernos de Saúde Pública, 36, e00122719. https://doi.org/10.1590/0102-311x00122719

[13] Geiss, O. and Kotzias, D. (2007) Tobacco, Cigarettes and Cigarette Smoke: An Overview. European Commission, Directorate-General, Joint Research Centre, 1-73.

[14] Landsberger, S. and Wu, D. (1995) The Impact of Heavy Metals from Environmental Tobacco Smoke on Indoor Air Quality as Determined by Compton Suppression Neutron Activation Analysis. The Science of the Total Environmental, 173-174, 323-337. https://doi.org/10.1016/0048-9697(95)04755-7

[15] U.S. Department of Health and Human Services (2010) How Tobacco Smoke Causes Disease: The Biology and Behavioral Basis for Smoking-Attributable Disease: A Report of the Surgeon General. U.S. Department of Health and Human Services, Centers for Disease Control and Prevention, National Center for Chronic Disease Prevention and Health Promotion, Office on Smoking and Health, Atlanta, GA.

[16] Harakeh, Z., Engels, R.C.M.E., Baaren, R.B. and Scholte, R.H.J. (2007) Imitation of Cigarette Smoking: An Experimental Study on Smoking in a Naturalistic Setting. Drug and Alcohol Dependence, 86, 199-206. https://doi.org/10.1016/j.drugalcdep.2006.06.006

[17] Atkins, P.W. and Jones, L. (2018) Princípios de Química-Questionando a vidamoderna e o meioambiente. Bookman Group, Orange, CA, 213 p.

[18] Davis, S.N., Whittmore, D.O. and Martin, J.F. (1998) Uses of Choride/Bromide Ratios in Studies of Potable Water. Groundwater, 36, 338-350. https://doi.org/10.1111/j.1745-6584.1998.tb01099.x

[19] Ayres, R.U., Norberg-Bohm, V., Prince, J., Stigliani, W.M. and Yanowitz, J. (1989) Industrial Metabolism, the Environment, and Applications of Materials-Balance. In: Principles for Select Chemicals, Chap. 2, International Institute for Applied Systems Analysis, Luxenburg, 17-47.

[20] Norberg-Bohm, V., Yanowitz, J. and Prince, J. (1988) Materials Balance for Bromine, Chlorine, Sulfur and Nitrogen in Europe. IIASA Working Paper. IIASA, Laxenburg, Austria: WP-88-073.

[21] Millaleo, R., Reyes-Diaz, M., Ivanov, A.G., Mora, M.L. and Alberdi, M. (2010) Manganese as Essential and Toxic Element for Plants: Transport, Accumulation and Resistance Mechanisms. Journal of Soil Science and Plant Nutrition, 10, 470-481. https://doi.org/10.4067/S0718-95162010000200008

[22] Li, L. and Yang, X. (2018) The Essential Elemento Manganese, Oxidative Stress, and Metabolic Diseases: Links and Interactions. Oxidative Medicine and Cellular Longevity, 2018, Article ID: 7580707. https://doi.org/10.1155/2018/7580707

[23] Alejandro, S., Hőller, S., Meier, B. and Peiter, E. (2020) Manganese in Plants: From Acquisition to Subcellular Allocation. Frontiers in Plant Science, 11, Article 300. https://doi.org/10.3389/fpls.2020.00300

[24] Etges, V.E. (2002) O impacto da cultura do Tabaco no ecossistma e nasaúdehumana. Ensaio, 1, 14-21.

[25] Saerens, A., Ghosh, M., Verdonch, J. and Godderis, L. (2019) Risk of Cancer for Workers Exposed to Antimony Compounds: A Systematic Review. International Journal of Environmental Research and Public Health, 16, Article 4474. https://doi.org/10.3390/ijerph16224474 
[26] Diaz, O., Figueiredo, A.M.G., Nogueira, C.A., Lopez, N., Gonzalez, H., Manso, M.V., Saiki, M. and Vasconcellos, M.B.A. (2005) Epithermal Neutron Flux Characterization of the IEA-R1 Research Reactor, Sao Paulo, Brazil. Journal of Radioanalytical and Nuclear Chemistry, 266, 153-157. https://doi.org/10.1007/s10967-005-0885-4

[27] Associação Brasileira de Normas Técnicas-ABNT, NBR 7181/2016 (2016) 2edição, Solo-Análisegranulométrica, Soil-Grain Size Analysis.

[28] Hamidatou, L., Slamene, H., Akhal, T. and Zouranen, B. (2013) Concepts, Instrumentation and Technique of Neutron Activation Analysis. In: Kharfi, Ed., Imaging in Interdisciplinary Research-Fundamentals and Cutting Edge Applications, Chap. 6, IntechOpen, London, 141-178. https://doi.org/10.5772/53686

[29] Nyarko, B., Akaho, E. and Armah, Y.S. (2003) Application of NAA Standardization Methods Using a Low Power Research Reactor. Journal of Radioanalytical and Nuclear Chemistry, 257, 361-366. https://doi.org/10.1023/A:1024744131848

[30] Silachyov, I. (2016) Rare Earths Analysis of Rock Samples by Instrumental Neutron Activation Analysis, Internal Standard Method. Journal of Radioanalytical and Nuclear Chemistry, 310, 573-582. https://doi.org/10.1007/s10967-016-4903-5

[31] Knoll, G.F. (2010) Radiation Detection and Measurement. 4th Edition, John Wiley \& Sons, New York.

[32] Roth, S., Grass, F., Corte, F., Moens, L. and Buchtela, K. (1993) Determination of Ko and Qo Factors of Short Lived Nuclides. Journal of Radioanalytical and Nuclear Chemistry, 169, 159-175. https://doi.org/10.1007/BF02046791

[33] Munita, C.S. and Mazzilli, B.P. (1986) Determination of Trace Elements in Brazilian Cigarette Tobacco by Neutron Activation Analysis. Journal of Radioanalytical and Nuclear Chemistry Letters, 108, 217-227. https://doi.org/10.1007/BF02164856 